\title{
CAPITAL ACCUMULATION AND CONVERGENCE IN A SMALL OPEN ECONOMY
}

\author{
PARTHA SEN \\ Email: partha@econdse.org \\ Faculty of Economics \\ South Asian University \\ $\&$ \\ Centre for Development Economics \\ Delhi School of Economics
}

Working Paper No. 212

Centre for Development Economics

Department of Economics, Delhi School of Economics 


\title{
CAPITAL ACCUMULATION AND CONVERGENCE IN A SMALL OPEN ECONOMY*
}

\author{
Partha Sen \\ Faculty of Economics \\ South Asian University \\ and \\ Centre for Development Economics \\ Delhi School of Economics \\ email: partha@econdse.org
}

\begin{abstract}
Outward-oriented economies seem to grow faster than inward-looking ones. Does the literature on convergence have anything to say on this? In the dynamic HeckscherOhlin-Samuelson model, with factor-price equalization, there is no convergence of incomes. This is because with identical preferences and return to capital, irrespective of initial levels the growth rates of consumption are the same. In the Specific Factors model, there is factor price equalization in the long run, but incomes depend on endowments of non-accumulable factors. Different specifications for the intersectorally mobile factors have different implications for development (as well as convergence). JEL Classification: F10, F11, F43.

Key Words: Convergence, Heckscher-Ohlin Model, Specific Factors Model, Land, Capital Accumulation.
\end{abstract}

* This is a much-revised version of invited presentations at the Queen Mary, University of London Workshop at Goodenough College, London in April 2011 and at the Asia Pacific Economic Forum in Tehran in October 2011. 


\section{INTRODUCTION}

In the last quarter of a century, there has been a revival of growth theory. In this revival among other questions (e.g. the central role of human capital formation and R \& D), a major line of enquiry has been whether economies "converge" as they accumulate capital. This is of particular interest since in the post-World War II period, some economies have seen spectacular growth, and in a generation they have moved from being poor to quite welloff. Empirical work has also established that in the cross-section data there is evidence of conditional (as opposed to absolute) convergence. That is, economies with similar legal and other institutional frameworks tend to converge (see Barro and Sala-i-Martin (2003) and Ventura (1997)).

What does growth theory predict about convergence? Initially the literature confined itself to a closed economy framework (either the Solow growth model or the Ramsey-CassKoopmans optimal growth model). These models predict absolute convergence (given identical tastes and technology parameters, of course). But in the last ten years or so, a few papers have appeared that look at the convergence issue in an open economy setting. This distinction is crucial because most of the economies that witnessed phenomenal growth in post-War period were not closed economies. In fact international trade (or openness) was central to their success. They relied on external markets, imported technology and had access to foreign capital (in varying degrees) ${ }^{1}$ — just consider the experience of Japan, China and the other East Asian economies.

The details of how capital accumulation affects an economy in a closed economy growth model, as opposed to an open economy model, are important. In closed economy growth models capital accumulation is accompanied by a decline in the rate of return to capital-there is an inverse relationship between the capital-labor ratio and the return to capital. In an open economy, as an economy accumulates capital its product-mix moves towards more capital-intensive goods. In the cone of diversification the factor prices do not change at all. If the rate of return is given, then the Rybczinski theorem predicts that with

\footnotetext{
${ }^{1}$ International capital mobility has been the focus of international finance models-see e.g., Obstfeld and Rogoff (1996). It is a moot point whether capital is really as mobile as these models assume. We look at the polar opposite case of no international capital mobility. Also see footnotes 6 and 9 below.
} 
capital accumulation there will be a contraction of the output of the labor-intensive good, while the production of the capital-intensive good expands.

Hitherto, most of the open economy literature has used the Heckscher-OhlinSamuelson (H-O-S) framework grafted on a Ramsey-Cass-Koopmans growth model. ${ }^{2}$ It is a natural first step in analyzing the issue of convergence in an open economy. Do economies with identical tastes and technology (the assumptions made in the H-O-S model) converge (in absolute terms)? The answer is, surprisingly, "No”. If there is factor-price-equalization (i.e. both economies are diversified in production), then with identical tastes, both countries' Euler equations are identical. And, therefore, their consumptions grow at the same rate irrespective of the initial levels of consumption. A capital-poor economy outside the diversification cone, will specialize completely in the labor-intensive good. This economy will continue to accumulate capital until it reaches the lowest capital-labor ratio of the world economy's diversification cone (assuming that the world economy is in steady-state) (see Chen (1992), Ventura (1997), Atkeson and Kehoe (2000), Cunat and Maffezzoli (2004a) (2004b), Bajona and Kehoe (2010) for further discussion).

Models based on Ricardian differences in technology can have something to say on the issue. ${ }^{3}$ Absolute advantage, that does not determine trade patterns in a static model, could also be useful in the discussion of convergence. Absolute advantage comes into its own because an economy, say, with equal (Hicks-Neutral) absolute advantage in both goods, will have a higher return to capital and hence a higher growth rate of consumption per capita. ${ }^{4}$ In the light of all this, one can then legitimately ask whether a dynamic international trade model based on factor endowments (with identical tastes and technology) has anything, if at all, to say on convergence?

In this paper, I use a dynamic specific factors model for a small open economy (SOE) to show that we can have convergence in factor rewards, but not necessarily in incomes. ${ }^{5}$ The

\footnotetext{
2 There are some two period overlapping generations models with H-O-S also (see e.g. Mountford (1998), Bajona and Kehoe (2006)).

${ }^{3}$ See Ventura (1997) and Bajona and Kehoe (2010) for Ricardian models.

${ }^{4}$ See e.g. Brecher, Chen and Choudhri (2002) and Chatterjee and Shukayev (2012))--these follow Trefler (1993), (1995); see also Harrigan (1997).

${ }^{5}$ In an earlier paper with the late Koji Shimomura (Sen and Shimomura (2010)), we had analyzed the dynamics in a two-country model with specific factors. In that paper, with a non-traded composite good made from two traded inputs, the emphasis was on the possibility or otherwise of a unique steady state in a specific factors model. In this paper the emphasis is on development and the role of the third factor of production (land).
} 
specific factors (also called the Ricardo-Viner) model also has a hoary tradition. The revival of this in recent times is due to Ronald Jones (Jones (1971)). ${ }^{6}$ The model has three factors of production producing two goods - a pure consumption good and an investment good (in the tradition of closed economy two-sector models (see e.g. Uzawa (1965)). In this set-up commodity price equalization does not imply factor price equalization. In particular the interest rate of the SOE is no longer tied to the world interest rate and the Euler equation for this economy guarantees convergence of factor returns only in the steady state.

The algebra of the dynamics of the specific factors model is straightforward. The interesting implications for economic development depend on the details of the interpretation that we give to the three factors. Thus, for instance, we can show labor moving away from the agricultural sector (i.e. industrialization) in the phase of convergence. But we can also suggest a reason why in the UK, the share of land in wealth after industrialization has dwindled to almost zero, but this is not the case for the US.

Over the recent years, there are a few dynamic models in the specific factors tradition, beginning with Eaton (1987), (1988) ${ }^{7}$. The specific factors model deserves more attention in its dynamic version than has been the case hitherto. We may recall that the first test of the Heckscher-Ohlin model, by Leontief, suggested that the model had erred in ignoring land as the third factor of production. Land is an important asset--an extremely important one in the early stages of development.

The paper is organized as follows: In section 2, we shall briefly review convergence in the closed economy optimal growth model. It is worthwhile doing this because the dynamics of the specific factors model (i.e. in its algebra) looks like this set up. In the following section, we introduce the open economy and discuss the H-O-S model, where factor price equalization does not imply convergence of incomes. In section 4, we look at the two cases of the specific factors model. Both give us convergence of factor prices in the

\footnotetext{
${ }^{6}$ Recent dynamic H-O-S models using the small open economy assumption include Atkeson and Kehoe (2000) and Chatterjee and Shukayev (2012),

${ }^{7}$ Eaton assumed capital was mobile internationally. That tied down the factor prices in his papers. In this paper, my objective is to analyze the evolution of these factor prices, as capital accumulation takes place. In this set-up capital mobility would make the economy jump to the steady state (as in Eaton's models). Adjustment costs of capital would be required to give transitional dynamics.
} 
steady state but national incomes, even in the steady state, depend on endowments. Finally, section 5 concludes.

\section{ECONOMIC GROWTH AND CONVERGENCE IN THE CLOSED ECONOMY}

Consider the Ramsey-Cass-Koopmans model. Output is produced using a linearhomogeneous technology using labor and capital. Labor grows exogenously and capital is accumulated through saving. As the capital-labor ratio rises, with capital accumulation, the rate of return to capital falls. A poorer economy with a lower capital-labor ratio has a higher rental rate and a higher growth rate.

We look at this model briefly here because in the later sections we shall be using variants of this model. Since in section 4, all the factors other than capital are inelastic in supply (and constant), in specifying the model in this section also we abstract from population growth and factor-augmenting technical change.

We look at competitive version of the model where households and firms maximize utility and profits over an infinite horizon. All agents possess perfect foresight.

Infinitely-lived households maximize a utility functional that is time separable with a constant rate of time preference:

$$
\int_{0}^{\infty}[u(C(t)) \exp .(-\theta t)] d t
$$

where $\mathrm{C}$ is consumption and $\theta$ is the rate of time preference. The instantaneous utility function u(.) satisfies: $u^{\prime}(C)>0, u^{\prime \prime}(C)<0, u^{\prime}(C)_{C \downarrow 0} \rightarrow \infty, \quad u^{\prime}(C)_{C \uparrow_{\infty}}=0$.

Along the optimal path we have the Euler equations

$$
\dot{C}(t) / C(t)=\mu(r(t)-\theta)
$$

where $\mu$ is the intertemporal elasticity of substitution. 
The firms maximize profits, $\pi(\mathrm{t})$, using a linear-homogeneous production function:

$$
\pi(t) \equiv F(K(t), L)-\delta K(t)-r(t) K(t)-w(t) L
$$

$\mathrm{F}$ is increasing in its arguments and homogeneous of degree one in the two inputs and is twice continuously differentiable. Both inputs are essential for production. It also satisfies the Inada conditions. The depreciation rate is given by $\delta$.

The dynamics of the economy is represented by (dropping the time index) ${ }^{8}$ :

$$
\begin{aligned}
& \dot{K}=F(K, L)-C-\delta K \\
& \dot{C} / C=\mu\left(F_{K}(K, L)-(\delta+\theta)\right)
\end{aligned}
$$

The economy has a trivial steady state with $\bar{C}=\bar{K}=0$. Its non-trivial steady state is obtained by setting equations (4a) and (4b) to zero:

$$
\begin{aligned}
& f(\bar{k})=\bar{C}+\delta \bar{k} \\
& f^{\prime}(\bar{k})=\delta+\theta
\end{aligned}
$$

The non-trivial steady state of this economy is unique. Equation 5(b) ties down the capital stock per capita, and equation (5a), in turn, ties down consumption per capita.

The absolute convergence story requires (5a), (5b) and 4(b). With preferences and technology the same between two countries, they will converge to the same steady state. Equation (4b) then tells us that the poorer economy's consumption grows faster because its capital stock is lower and, therefore, its return to capital is higher.

\footnotetext{
${ }^{8}$ Equation (4b) is obtained by setting $r=\delta+\theta$.
} 


\section{THE OPEN ECONOMY: HECKSCHER-OHLIN-SAMUELSON}

We extend the Ramsey-Cass-Koopmans model to the open economy. We will, as mentioned above, abstract from international borrowing or lending. Hence an open economy model requires trade be balanced. This, in turn, requires at least two goods.

It is very natural to think of the H-O-S framework as the natural extension when one wants to embed the Ramsey-Cass-Koopmans model in an open economy setting. It is the framework used in the recent literature on the issue of convergence with international trade. In the context of convergence (and development), we could ask what does capital accumulation imply for a SOE?

In the H-O-S set-up studied in this section, there are two goods-a pure consumption good, C, and a pure investment good, M (in the tradition of Oniki and Uzawa (1965)). ${ }^{9}$ These are produced using labor and capital (the latter is accumulable) with both inputs being mobile across sectors. In section 4 when we study the specific factors model, these goods are produced using three factors of production, with one of them being mobile intersectorally, and the other two are specific to sectors.

The SOE produces the two goods and these outputs are traded internationally and the desired levels of the consumption and investment goods are purchased. Comparative advantage is determined by factor endowments. Trade in the two outputs requires (a variable with a tilde denotes the quantity produced domestically of that good):

$$
C+q M=\tilde{C}+q \tilde{M}
$$

The C-good is the numeraire and $\mathrm{q}$ is the (free trade) relative price of the M-good (taken as parametrically given by the SOE). Note that we have assumed that trade is balanced, i.e. there is no borrowing or lending.

${ }^{9}$ We could equivalently model production of the two goods (i.e. $\tilde{C}$ and $\tilde{M}$ ) to be traded for intermediate inputs (C and $\mathrm{M}$ ) in the international markets into a homogeneous final good (Q) that is used for consumption $(\mathrm{H})$ and investment. Then the model would become:

$\widetilde{C}+q \tilde{M}=C+q M, Q=J(C, M), \dot{K}=Q-H-\delta K$. See Atkeson and Kehoe (2000), Bajona and Kehoe (2006), (2010) for different types of modeling strategies. 
The representative consumer maximizes the utility functional given in equation (1) with the same restrictions on the instantaneous utility function.

Turning to the production side, there are two inputs capital and labor that are mobile across sectors. Perfect competition prevails.

$$
\widetilde{C}=F\left(L^{C}, K^{C}\right)
$$

F is increasing in its arguments and homogeneous of degree one in the two inputs and is twice continuously differentiable. Both inputs are essential for production. It also satisfies the Inada conditions.

The M good is also produced via a linear homogeneous technology $G($.$) that satisfies$ positive but diminishing marginal products for factors. Essentiality of inputs, twice continuous differentiability and Inada conditions hold.

$$
\tilde{M}=G\left(L^{M}, K^{M}\right)
$$

Full employment for $\mathrm{L}$ and $\mathrm{K}$ give us

$$
\begin{aligned}
& L=L^{C}+L^{M} \\
& K=K^{C}+K^{M}
\end{aligned}
$$

The production decision can be summarized by defining the GDP function R(1.q.K):

$$
R(1, q, K) \equiv \max _{K^{C}, K^{M}, L^{C} . L^{M}}\left\{F\left(K^{C}, L^{C}\right)+q G\left(K^{M}, L^{M}\right) \mid K^{C}+K^{M}=K, L^{C}+L^{M}=L\right\}
$$

The maximization problem of the firm in (10) then involves capital and labor moving across the two sectors till their marginal products (in value terms) get equalized.

$$
F_{K}\left(K^{C}, L^{C}\right)=q G_{K}\left(K^{M}, L^{M}\right)
$$


$F_{L}\left(K^{C}, L^{C}\right)=q G_{L}\left(K^{M}, L^{M}\right)$

The dynamics of the economy is represented by:

$$
\begin{aligned}
& q \dot{K}=R(1, q, K)-C-\delta q K \\
& \dot{C} / C=\mu\left(\left(R_{K} / q\right)-(\delta+\theta)\right)
\end{aligned}
$$

Equation (12a) is the saving equal to investment relationship-because of balanced trade, savings can to accumulate capital (as opposed to running up claims against the rest of the world if trade were not balanced). Equation (12b) is the Euler equation.

Let us now analyze the behavior of this model at any given instant. From the linearhomogeneity of $\mathrm{F}($.$) and \mathrm{G}($.$) we can write (11a) and (11b) in terms of the intensive$ magnitudes ( $\mathrm{k}^{\mathrm{i}}$ is the capital-labor ratio in sector $\left.\mathrm{i}, \mathrm{i}=\mathrm{C}, \mathrm{M}\right)$ :

$$
\begin{aligned}
& f^{\prime}\left(k^{C}\right)=q \cdot g^{\prime}\left(k^{M}\right) \\
& f\left(k^{C}\right)-k^{C} f^{\prime}\left(k^{C}\right)=q\left[g\left(k^{M}\right)-k^{M} g^{\prime}\left(k^{M}\right)\right]
\end{aligned}
$$

Incomplete specialization, from equations (13a) and (13b) implies factor-priceequalization (the Samuelson part of the H-O-S). This is because given q, if the SOE has endowments of factors that lie in the cone of diversification for the world economy, these equations determine $\mathrm{r}$ and $\mathrm{w}$ for the SOE. Hence the absence of international borrowing or lending (remember we have ruled this out by assumption) is no longer relevant - trade in goods provide these "missing markets".

If, on the other hand, the SOE lies outside the cone of diversification (in a development context, with too little capital), then it specializes in the production of one (labor-intensive) good. Let us take this to be the C-good. Factor prices are no longer equalized internationally. Then we have:

$$
\begin{aligned}
& r=f^{\prime}\left(k^{C}\right) \\
& w=f\left(k^{C}\right)-k^{C} f^{\prime}\left(k^{C}\right)
\end{aligned}
$$


Let us look at the implications of these two possibilities for convergence. Imagine the world economy (OECD) is in a steady state equilibrium, and the SOE takes all international prices and quantities as given.

If factor price equalization occurs, then with identical tastes (and technology), the interest rate facing the economy under consideration equals that in the rest of the world. If the rest of the world is in a steady state, as we have assumed, then so is the small open economy i.e.

$$
r(t)=r^{W}=\theta+\delta \quad \forall t
$$

Even if the world economy is not in steady state, the Euler equations ensure that growth rate of consumption of the SOE is equal to the world economy (where the superscript W refers to the world economy):

$$
\dot{C}(t) / C(t)=\mu(r(t)-(\theta+\delta))=\dot{C}^{W}(t) / C^{W}(t)
$$

As Chen (1992) first showed, this result in a dynamic optimal growth framework results in hysteresis-i.e. non-convergence. ${ }^{10}$ A country with a higher income has the same growth rate of consumption per capita as its poorer trading partner, implying thereby that the initial discrepancy in consumption levels is never eliminated. ${ }^{11}$

In the other case (i.e. when the SOE lies outside the diversification cone), the SOE approaches the world economy with

$$
r(t)>r^{W}=\theta+\delta
$$

\footnotetext{
${ }^{10}$ The Euler equations for the SOE and the world economy would be identical, implying a zero root in the coefficient matrix of the dynamic system.

${ }^{11}$ This result is true of a Ramsey-Cass-Koopmans model with a H-O-S trade structure. In an overlapping generations model (of the two-period or the Blanchard-Yaari-Weil type) it does not hold. It would also not hold if the rate of time preference was variable (a la Uzawa).
} 
It continues to produce the labor-intensive good until it reaches the edge of the cone of diversification for the world economy. As soon as it reaches the minimum capital-labor ratio of this cone, its capital accumulation ceases because now (equation (15a) above) $r(t)=r^{W}=\theta+\delta$.

Thus, it remains at the lowest level of the aggregate capital-labor ratio of the world economy. Thus here to paraphrase Atkeson and Kehoe (2000), the "late-bloomers" never catch up with the "early-bloomers". 1213

\section{DYNAMIC SPECIFIC FACTORS MODELS}

We now turn to the specific factors model. The two goods are now produced with three inputs, one of which is mobile across sectors. Preferences and the trade pattern are unchanged from the previous section. The rest of the world has a similar production structure but is in steady-state- these imply given rate of return to capital, $\mathrm{r}^{\mathrm{W}}$, wage rate, $\mathrm{w}^{\mathrm{W}}$, and return to land, $\mathrm{s}^{\mathrm{W}}$.

Economic development involves capital accumulation (physical and human). In some cases capital deepening takes place in all the sectors of the economy, so that industry and a land-dependent activity develop side-by-side. The land-dependent activity could be plantations (Malaysia), tourism (Thailand, South Africa), or hydroelectricity (Nepal, Bhutan). In the other case, capital accumulation occurs in one sector and is accompanied by a process of "structural transformation", whereby labor is relocated from agriculture to industry. This is the typical Lewis-type surplus labor situation followed by migration to the city. We look at both of these possibilities in turn.

I also note that the discussion in this paper is about the adjustment path of development. The economy considered has no indivisibilities or externalities that have given

\footnotetext{
${ }^{12}$ If capital were mobile internationally, then the poor country would borrow to arrive at the lower boundary of the "OECD" capital-labor ratio.

${ }^{13}$ Mountford (1998), in a two period overlapping generations structure with a H-O-S trade pattern grafted on it, shows that two economies can converge to different to different steady states. His results depend on the existence of multiple steady states.
} 
rise poverty traps in closed economy models (e.g. Azariadis and Drazen (1990), Azariadis (1996) and Ceroni (2001)). ${ }^{14}$

\subsection{Capital as the Mobile Factor}

The two goods, $\mathrm{C}$ and $\mathrm{M}$, are produced using three factors of production $(\mathrm{K}, \mathrm{L}$ and D). ${ }^{15}$ Capital $\mathrm{K}$ is mobile across sectors, ${ }^{16}$ whereas $\mathrm{D}$ and $\mathrm{L}$ are specific to sectors $\mathrm{C}$ and $\mathrm{M}$ respectively.

$$
\widetilde{C}=F\left(D, K^{C}\right)
$$

As before, $\mathrm{F}$ is increasing in its arguments and homogeneous of degree one in the two inputs and is twice continuously differentiable. Both inputs are essential for production. It also satisfies the Inada conditions--for capital it implies that it would be employed in both sectors.

The M good is also produced via a linear homogeneous technology G(.) that satisfies positive but diminishing marginal products for factors. Essentiality of inputs, twice continuous differentiability and Inada conditions hold.

$$
\tilde{M}=G\left(L, K^{M}\right)
$$

For capital we have the full employment condition:

$$
K=K^{C}+K^{M}
$$

We assume in this paper, that only capital can be accumulated, while the levels of the other two factors are constant. We also assume that the home economy is differently

\footnotetext{
${ }^{14} \mathrm{I}$ am grateful to a referee for pointing me towards this literature.

${ }^{15}$ It is not important whether the two goods are pure consumption and investment goods, since the small open economy faces a given terms of trade. Where the economy in question can affect the relative price of the goods in the world markets, the identification of the two goods as investment and consumption is not innocuous.

${ }^{16}$ Neary (1978) had different capitals as specific factors, with labor mobile. In the long-run capital moved between sectors and the model collapsed to the H-O-S model. The specific factor model in this paper is not so ephemeral because there are two primary inputs.
} 
endowed in the latter factors compared to the rest of the world (the rest of the world is assumed to be in steady state, as in the previous section).

$$
D / L \neq D^{W} / L^{W}
$$

Before turning to analyzing the model, note that in our model there is incomplete specialization. If full employment is assumed for the specific factors, issues of diversification that are important in the H-O-S framework, do not arise here-the entire plane with $\mathrm{L}$ and D on the axes is the cone of diversification. In either sector, full employment of the fixed factor requires some capital — we have assumed both factors are essential for production-and initially capital flows to the sector because of the Inada condition.

To analyze the model, we first define the GDP function - this can be thought of as the solution to the firms’ maximizing problem:

$$
R(1, q, K) \equiv \max _{K^{C}, K^{M}}\left\{F\left(K^{C}, D\right)+q G\left(K^{M}, L\right) \mid K^{C}+K^{M}=K\right\}
$$

We have from this (since only capital is mobile):

$$
F_{K}\left(K^{C}, D\right)=q G_{K}\left(K^{M}, L\right)
$$

Thus, given the capital stock in each economy and the relative price, capital moves across the sectors till its marginal revenue product is equalized.

Free trade of good is still given by equation (6):

$$
C+q M=\tilde{C}+q \tilde{M}
$$

The dynamic equations are:

$$
\begin{aligned}
& q \dot{K}=R(1, q, K)-C-\delta q K \\
& \dot{C} / C=\mu\left(\left(R_{K} / q\right)-(\delta+\theta)\right)
\end{aligned}
$$


Comparing (11a) and (11b) with (22a) and (22b), we note that except the GDP function, they are very similar. However, one should not be deceived by this. We shall get convergence of factor returns only in the steady state but not outside it. We will also see the equality of factor returns in steady state will coexist with differences in per capita income.

There is, as before, a trivial steady state of this model and is given by $\bar{K}=\bar{C}=0$. The unique non trivial steady state is given by:

$$
\begin{aligned}
& \bar{M}=\delta \bar{K} \\
& F_{K}\left(\bar{K}^{C}, D\right)=q \cdot(\delta+\theta) \\
& F_{K}\left(\bar{K}^{C}, D\right)=q G_{K}\left(\bar{K}-\bar{K}^{C}, L\right)
\end{aligned}
$$

Note that in the steady state, any economy with the same tastes and technology and facing the same price ratio q, will have the same capital-labor ratio and capital -land ratio:

$$
\begin{aligned}
& \left(\bar{K}^{C^{W}} / D^{W}\right)=\left(\bar{K}^{C} / D\right) \\
& \left(\bar{K}^{M^{W}} / L^{W}\right)=\left(\bar{K}^{M} / L\right)
\end{aligned}
$$

Thus there is factor-price equalization in the steady state. This, we shall see, does not happen outside the steady state.

Does this imply that there is income convergence also in the steady state? Remember in the H-O-S model that was not so. When the economies were in the same cone of diversification, the capital-poor country stayed poor, albeit now with identical returns to the two factors. On the other hand, when it was outside the cone of diversification, it attained a steady state that was the lowest capital-labor ratio in the cone of diversification. This is not so in the specific factors model. In particular, if this economy has a larger land per capita, then its per capita income will be higher than the world economy's. This is true in the steady state no matter where the small open economy in question starts off from. 
Since the SOE is assumed different in the ratios of $\mathrm{D} / \mathrm{L}$, if it is the economy with a higher $\mathrm{D} / \mathrm{L}$ ratio, it will have higher consumption and investment in the steady state. Capital in the steady state is "obtainable" at a fixed price $(\delta+\rho)$. Thus an economy with a higher $\mathrm{D} / \mathrm{L}$ ratio will have more capital per capita so that the ratio of capital to land in the $\mathrm{M}$ sector is also equalized internationally. We have then:

$$
\{(\bar{C} / L)+q \cdot(\delta \bar{K} / L)\}=f\left(\bar{K}^{C} / D\right) \cdot(D / L)+q \cdot g\left(\bar{K}^{M} / L\right)
$$

In equation (25), $f($.$) and g($.$) are respectively the per unit of land output in the C$ sector and per capita output in the M sector. Per capita output in the M-sector in the steady state is just replacement investment. From factor price equalization, f(.) and g(.) are equalized internationally. Hence per capita income depends solely on the ratio D/L. In particular, an economy with higher endowment of land per capita, will have a higher per capita income in the steady state.

We now analyze the dynamics of the model. Linearizing the two differential equations around the initial steady state and writing in a matrix form, we have:

$$
\begin{aligned}
& {\left[\begin{array}{c}
\dot{C} \\
q \dot{K}
\end{array}\right]=\left[\begin{array}{cc}
0 & \mu q^{-1} F_{K K} \\
-1 & R_{K}-\delta q
\end{array}\right]\left[\begin{array}{c}
C-\bar{C} \\
K-\bar{K}
\end{array}\right]} \\
& \operatorname{det} . A=\mu q^{-1} F_{K K}<0 \\
& x=\left(\sigma_{S}\right) /\left(\mu q^{-1} F_{K K}\right)>0
\end{aligned}
$$

In equation (27a) we find that the determinant of the coefficient matrix $\mathrm{A}$ in equation (26) is negative. ${ }^{17}$ Thus the steady-state is a saddle-point and $\mathrm{x}$ in (27a) gives the slope of the stable arm in the K-C plane. The phase diagram of the dynamic system given by (26), looks like the closed economy Ramsey model. In particular, the stable arm is upward-sloping (from (27b)). Hence along the optimal path $\mathrm{C}$ and $\mathrm{K}$ move together. But the interpretation of the dynamics, and in particular, the developmental implications of convergence are very

\footnotetext{
${ }^{17}$ The determinant is product of the characteristic roots. If it is negative, the roots are real and of opposite sign. We call the stable root $\sigma_{s}$. The eigen-vector “associated” with this root is $(1, \mathrm{x})$ ', where $\mathrm{x}$ is given in (27b).
} 
different. Even within the class of open economy specific factors model, we can have vastly different results depending on the postulated structure (as we shall see in section 4.2).

A capital-poor developing country starts out with a high return to capital and low returns to the other factors-labor and land. As capital is accumulated, the returns to these factors rise. Along the stable arm, consumption and the capital stock rise, with a fall in the rate of return to capital. In the steady state, this rate of return is given by $\theta+\delta$ (as in the closed economy). The return to labor and land is also, with identical technologies, equalized internationally. But as equation (25) above shows, if the SOE is land-abundant, then its percapita income will be higher than the world economy's per capita income. Natural resources are clearly not a curse here. ${ }^{18}$ Across steady states, land (and labor) cause a "crowding in" of capital. We will see that in the next example, with labor being the mobile factor across sectors (as in Eaton (1987), (1988)), the picture will be very different. Land and capital will become substitutes.

We can imagine that the SOE starts off from a very low level of capital, while being endowed with a lot of land. But in the new steady state, an initially poorer economy overtakes the richer (world) economy. Contrast this with the findings of Atkeson and Kehoe (2000), where the poorer economy stays poorer forever.

Finally, I point out that although there are two factors that are in given supply, we can still talk about a capital-rich and capital-poor economy. This is because of equation (21). The given goods price determines the ratio of the marginal products of capital:

$$
q=F_{K}(.) / G_{K}(.)
$$

Thus even if there is a lot of land and very little labor, capital moves until the ratio of marginal products equals the commodity price ratio.

We show the working of this specification of the specific factors model in Figure 1. O is the origin for the C-sector and $\mathrm{O}$ ' for the $\mathrm{M}$ sector. The marginal productivity of capital

\footnotetext{
${ }^{18}$ By natural resources, I do not mean extractable resources like oil or minerals. In this context it means nondegrading land, or a river.
} 
depends on the levels of the Edgeworth-complementary inputs. With a low capital stock initially, the short-run equilibrium is at point A. This shows a high rate of return to capital and low returns to $\mathrm{L}$ and $\mathrm{D}$ (the latter factors earn rents given by the triangles above $\mathrm{A}$ ). As capital accumulation occurs, the total capital stock is given by OO”. The steady state is given by point $\mathrm{B}$ - the returns to the fixed factors have risen compared to the $\mathrm{A}$

We now turn to one aspect of the land input that we have ignored so far. We have been talking of $\mathrm{D}$ as land but land is a durable factor of production. The return to holding land does not consist of just its marginal product but also the capital gains. Then arbitrage between the return to capital and land requires (assume land does not depreciate):

$$
\left(\left(R_{K} / q\right)-\delta\right)=\left(F_{D}+\dot{p}\right) / p
$$

The return to land in (28) consists of its marginal product $\mathrm{F}_{\mathrm{D}} / \mathrm{p}$ and the capital gains $\dot{p} / p$, where $\mathrm{p}$ is the relative price of land (in terms of the numeraire).

Solving the differential equation (28) "forward" and imposing a transversality condition, we find that the price of land is given by the present discounted value of the marginal product of land, where the (time-varying) discount factor is the return to capital.

$$
p(t)=\int_{t}^{\infty} e^{-\int_{t}^{s}\left[q^{-1} R_{K}(v)-\delta\right] d v} F_{D}(s) d s
$$

In the infinitely-lived-agent framework of this model, $\mathrm{p}(\mathrm{t})$ does not affect the other equations-this is in sharp contrast to, say, a two-period overlapping generations model where the value of land jostles with capital as a store of value for the saving by the young. ${ }^{19}$ Hence, in our model the dynamics of the SOE can still be characterized by the system given in (26), with the land price differential equation (28) ensuring continuous equilibrium in the markets for land.

\footnotetext{
${ }^{19}$ In the two-period overlapping generations version of the specific factors model, land constitutes part of the savings of the young and hence the dynamics of the model depends on the value of land (see Eaton (1987), (1988)). In a continuous time overlapping generations model of the Blanchard-Yaari -Weil type, a higher land value will cause a larger divergence between the average and marginal Euler equations.
} 


\subsection{Labor as the Mobile Factor}

Let us turn to the other possibility, namely, that one of the factors that is in given supply (e.g. labor) is the mobile factor-land continues to be specific to a sector. ${ }^{20}$ In the context of development, it is easy to think of $\mathrm{M}$ sector as industry that uses labor and the accumulable factor $\mathrm{K}$, with $\mathrm{K}$ now being specific to the $\mathrm{M}$ sector. The other good $\mathrm{C}$ is the consumption good (think of this as food) that is produced using sector-specific land and the intersectorally mobile labor.

How does this set-up differ from the previous example with the accumulable factor being mobile across sectors? Contrary to one's prior beliefs, it differs quite a lot. As an illustration consider the fact that in industrialized countries the share of land in total wealth had fallen progressively. Laitner (2000), for instance, reports the following: For the US, all private land constituted 31 percent of total wealth in 1900 and 16 percent in 1958. For the UK, it was 55 percent in 1798, 18 percent in 1885 and 4 percent in 1927.

A two-factor model cannot address this question but can our model reproduce this? The answer is "yes, it can". In particular, the fact that a land-poor economy will have the share of land going to zero is established below.

In any case, the formulation with labor being the mobile factor across sectors is very attractive in an industrialization context. In the initial stages of development, when a country is capital poor, most of the labor force is employed in the agricultural sector. We abstract from an Arthur Lewis-type situation, where the labor force in agriculture is so large that its marginal productivity is zero or even negative (this is in fact achieved by the Inada conditions that ensure that marginal productivities become zero only when the inputs go to infinity). ${ }^{21}$

As the economy accumulates capital, labor is drawn into industry. The process of this labor drain continues until a steady state is reached. Unlike our model with the relative price of the final goods being determined in the world market, if the price of the agricultural good

\footnotetext{
${ }^{20}$ Think of labor as raw labor and not human capital. In the first stages of development in most countries, unskilled labor is moved from agriculture to industry. Only later does a country move up the "quality ladder" and start producing goods that require substantial human capital.

${ }^{21}$ See e.g. Kanbur and Mclintosh (1988) and Temple (2005).
} 
were endogenous, the rise in the price of the agricultural good would slow down the movement of labor to the industrial sector.

Let us turn to the formal model. It is now labor (given in fixed supply) that is mobile and not capital (that can be accumulated). Capital is now used only in the $\mathrm{M}$ sector. $\mathrm{M}$ is produced using labor and capital, and $\mathrm{C}$ uses labor and the other factor, land (D). That is:

$$
\begin{aligned}
& \tilde{M}(t)=F\left(L^{M}(t), K(t)\right) \\
& \tilde{C}(t)=G\left(L-L^{M}(t), D\right)
\end{aligned}
$$

In the model now,

$$
R(1, q, K) \equiv \max _{L^{M}, L^{C}}\left\{F\left(L^{M}, K\right)+q G\left(L^{C}, D\right) \mid L^{M}+L^{C}=L\right\}
$$

The marginal product of labor is now equalized across sectors;

$$
F_{L}\left(L^{M}, K\right)=q G_{L}\left(L-L^{M}, D\right)
$$

How does the dynamic analysis change? Algebraically, it does not change very much. But now as capital is accumulated, instead of both sectors output expanding, the G sector contracts. Industry sucks out labor from agriculture in the process of capital accumulation and growth.

The steady state is given by equations (23a) and (23b) plus (32). In (23a), we have: $\bar{R}_{K}\left(=F_{K}\right)=q(\delta+\rho)$.

In the model of section 4.1, a higher land endowment calls forth higher capital accumulation. Loosely speaking, there across steady states, land and capital are complements. In the example of this section, land and capital are substitutes. A high land endowment per capita implies a higher wage rate and a lower capital stock. This is because the rental rate is driven down "very quickly" to its steady state value. 
One comparative dynamic exercise that may help resolve the differing experience of the UK and the USA mentioned above is the following: A higher land endowment (per capita) is a higher wage economy. This, in turn, implies that a higher land endowment per capita is, ceteris paribus, a lower rental rate (of capital) economy. Thus the steady state that is attained by accumulation of capital is approached "quickly" i.e. very little capital needs to be accumulated. A higher land economy is then a lower capital economy in the steady state (of course, the intensive magnitudes, i.e. land to labor in C, capital to labor in $\mathrm{M}$, are equalized internationally). This also means that a higher land per capita economy is blessed and cursed. Cursed because it will never industrialize as much as a low land endowment economy (this could be important outside, though not within, the narrow confines of our model). Blessed because industrialization means capital accumulation and that implies consuming less than one's income along the adjustment path—the land-rich economy does not need to do very much belt-tightening in this regard.

The working of the model in this sub-section is shown in Figure 2. In contrast to Figure 1, the horizontal axis is the given amount of labor. The initial equilibrium is at point A. As capital accumulation (synonymous with industrialization) occurs, labor moves to the $F$ sector. The steady state is at B. A land-rich economy starts out at C and has a steady state with D.

Note that the two cases studied so far in this section exhaust all the possible cases of the specific factors model in a dynamic setting, namely either the accumulable factor is the mobile one, or it is specific to a sector.

\section{CONCLUSIONS}

We started by pointing out that closed economy models are not the right structure to analyze convergence, or the lack of it, in the data. Models with international borrowing or lending, unless they tackle agency problems seriously, are ill-suited for the task. Thus we considered only models with no international borrowing or lending.

The popular H-O-S model grafted on to an optimal growth model is the obvious candidate to be considered for the task at hand. It surprisingly, produces no convergence (i.e., catch-up by the poor), even though it allows for factor-price-equalization. We then turned to a 
specific factors set up. We showed that there is convergence in a dynamic specific factors model with two primary factors of production. Only in the steady state is there equalization of factor prices. In the transition there is no factor price equalization. This happens even though the economy always produces both goods. This is in contrast to the H-O-S model where incomplete specialization implies factor-price equalization.

We also showed (section 4.1 above) that in a specific factor optimal growth model, a late-bloomer can overtake the (world) economy that has a head-start. This is because in the steady state with all relative input ratios equalized, an economy with higher per capita land endowment will have a higher per capita income.

We examined two versions of the specific factors model and found that we can get insights into the development process by studying the two versions-these give starkly contrasting predictions. When labor is mobile between sectors, the sector using land contracts as capital is accumulated. On the other hand, if capital is the mobile factor, we get a balanced growth prediction i.e. both sectors expand as capital accumulation takes place.

These results seem to suggest that it is too early to write an obituary of factor endowment models. Specific factors models can give sensible conclusions not only in a convergence context, but also shed light on the development process itself. 


\section{References}

Atkeson, Anthony, and Patrick J. Kehoe (2000) "Paths of Development for Early- and Late-boomers in a Dynamic Heckscher-Ohlin Model,” Research Staff Report No. 256, Federal Reserve Bank of Minneapolis.

Bajona, Claustre and Timothy J. Kehoe (2006) "Demographics in Dynamic Heckscher-Ohlin Models: Overlapping Generations versus Infinitely Lived Consumer,” Research Staff Report No. 377, Federal Reserve Bank of Minneapolis.

-(2010) “Trade, Growth, and Convergence in a Dynamic HeckscherOhlin Model,” Review of Economic Dynamics, 13, 487-513.

Cunat, Alejandro, and Marco Maffezzoli (2004a) “Heckscher-Ohlin Business Cycles” Review of Economic Dynamics 7,555-585.

Economic Dynamics, 7, 707-736.

(2004b) “Neoclassical Growth and Commodity Trade” Review of

Barro, Robert J. and Xavier Sala-i-Martin (2003) Economic Growth, Second Edition, MIT Press.

Brecher, Richard A., Zhiqi Chen, and Ehsan U. Choudhri (2002) “Absolute and Comparative Advantage, Reconsidered: The Pattern of International Trade with Optimal Saving” Review of International Economics, 10, 645-656.

Chatterjee, Partha Sarathi and M. Shukayev (2012) "Convergence in a Stochastic Dynamic Heckscher-Ohlin Model," Journal of Economic Dynamics and Control (forthcoming).

Chen, Zhiqi (1992) “Long-run Equilibria in a Dynamic Heckscher-Ohlin Model”, Canadian Journal of Economics 23, 923-43.

Eaton, Jonathan (1987) “A Dynamic Specific-Factors Model of International Trade”, Review of Economic Studies, 54, 325-338.

(1988) “Foreign-Owned Land”, American Economic Review, 78, 76-88.

Harrigan, James, (1997) “Technology, Factor Supplies and International Specialization: Estimating the Neoclassical Model,” American Economic Review, 87, 475494. 
Jones, Ronald W. (1971) “A Three-Sector Model in Theory, Trade, and History,” in Bhagwati, J.N., R.W. Jones and J. Vanek (eds.) Trade, Balance of Payments and Growth, (North-Holland Publishing Company, Amsterdam).

Mountford, Andrew (1998) “Trade, Convergence and Overtaking” Journal of International Economics 46, 167-182.

Neary, Peter, (1978) "Short-Run Capital Specificity and the Pure Theory of International Trade”, Economic Journal, 88, 488-512.

Obstfeld, Maurice, and Kenneth Rogoff (1996) Foundations of International Macroeconomics (MIT Press; Boston and London).

Onika, Hajime and Hirofumi Uzawa (1965) "Patterns of Trade and Investment in a Dynamic Model of International Trade” Review of Economic Studies 32, 15-38.

Sen, Partha, and Koji Shimomura (2010) “Convergence in a Two-Country Dynamic Trade Model” Delhi School of Economics Mimeo.

Trefler, Daniel (1993) "International Factor Prices: Leontief Was Right!" Journal of Political Economy, 111, 961-87.

- (1995) “The Case of Missing Trade and Other Mysteries,” American

Economic Review, 85, 1029-46.

Ventura, Jaime (1997), “Growth and Interdependence," Quarterly Journal of Economics, 112, 57-84. 

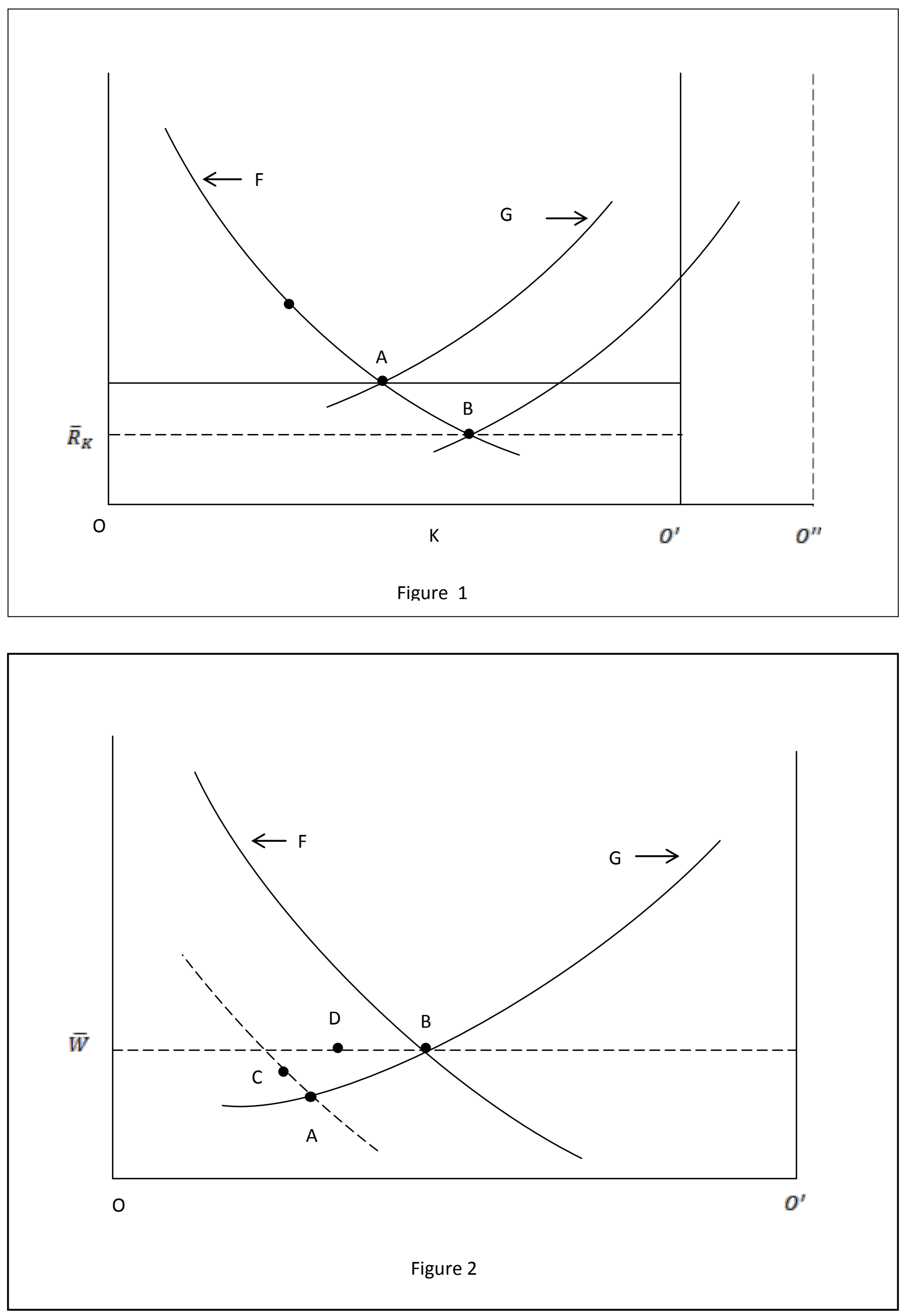